\title{
Ensino de Matemática no Curso Técnico Integrado em Edificações e Informática: reflexões a respeito de uma ação realizada
}

\section{Susimeire Vivien Rosotti de Andrade}

susivivien@hotmail.com

Universidade Estadual do Oeste do Paraná | Brasil

\section{Adriana Stefanello Somavilla}

adriana.soma@ifpr.edu.br

Instituto Federal do Paraná | Brasil

\section{Resumo}

0 objetivo deste texto é apresentar reflexões das contribuições para o desenvolvimento matemático dos alunos do $1^{\mathrm{o}}$ ano do curso Técnico Integrado em Edificações e Informática do Instituto Federal do Paraná - Campus de Foz do Iguaçu (PR), no decorrer da participação do projeto de extensão desenvolvido semanalmente no segundo semestre do ano de 2013. Os resultados das avaliações dos alunos participantes do indicaram melhoria gradativa no desempenho escolar em matemática e disciplinas afins. 0 desenvolvimento das atividades em turno oposto e de forma facultativa, com maneiras diferentes de abordar os conteúdos e a avaliação, oportunizou um ambiente crítico e de autonomia para o processo de ensino e aprendizagem.

\section{Palavras-chave}

Extensão; parceria institucional; oficinas pedagógicas. 


\section{Introdução}

No Brasil, as políticas educacionais que visam à integração do ensino médio com o profissional não são recentes, como os apontamentos de que esta modalidade de ensino deve garantir aos alunos uma formação geral, pois a educação técnica não conseguirá consolidar-se se não houver, concomitantemente, uma formação geral. Sendo assim, torna-se importante que:

[...] a qualificação profissional passe a repousar sobre o conhecimento e habilidades cognitivas e comportamentais que permitam ao cidadão/produtor chegar ao domínio intelectual da técnica e das formas de organização social, de modo que seja capaz de criar soluções originais para problemas novos, que exigem criatividade, pelo domínio do conhecimento (KUENZER, 2000, p. 19).

Neste sentido, visando a contribuir com o processo de ensino e aprendizagem de matemática dos alunos do $1^{\underline{0}}$ ano do ensino médio, do curso de Técnico Integrado em Edificações e Informática, estabeleceu-se uma parceria entre o curso de Licenciatura em Matemática da Universidade Estadual do Oeste do Paraná - Campus de Foz do Iguaçu e o Instituto Federal do Paraná - Campus de Foz do Iguaçu, na qual, as autoras deste texto elaboraram um projeto de extensão e contaram com a participação de quatro acadêmicos do curso de Licenciatura em Matemática. Cabe ressaltar que os acadêmicos colaboradores eram bolsistas do Programa de Extensão coordenado pela primeira autora.

Compreende-se que a extensão universitária vai ao encontro de Freire (1979), entendida como ação educativa na qual o extensionista tem claro que sua função não é uma mera ajuda voluntária, mas sim busca estender conhecimentos sistematizados que contribuirão com todos envolvidos, inclusive ele. Todavia, a história da extensão universitária denota o desconhecimento da Universidade a respeito da cultura e do saber popular evidenciando um posicionamento autoritário que não compreende que

Educar e educar-se, na prática da liberdade, não é estender algo desde a "sede do saber", até a "sede da ignorância" para "salvar", com este saber, os que habitam nesta. Ao contrário, educar e educar-se, na prática da liberdade é tarefa daqueles que sabem que pouco sabem - por isto sabem que sabem algo e podem assim chegar a saber mais - em diálogo com aqueles que, quase sempre, pensam que nada sabem, para que estes, transformando seu pensar que nada sabem em saber que pouco sabem, possam igualmente saber mais. (FREIRE, 2006, p. 25).

Neste sentido, justifica-se o desenvolvimento do projeto de extensão pela importância de se aproximar dos alunos que apresentavam dificuldade no decorrer das aulas de matemática e 
Ensino de Matemática no Curso Técnico Integrado em Edificações e Informática

nas áreas afins, contribuindo, consequentemente, com a formação de professores e de futuros professores participantes do projeto, além de auxiliar a Universidade a cumprir com a sua função social, potencializando-a como eixo articulador entre o ensino, pesquisa e extensão.

Os alunos do primeiro ano do Ensino Médio do Instituto, da turma de Edificações e Informática, foram convidados a participar, no turno contrário das atividades, de um estudo semanal de apoio pedagógico de Matemática no próprio Instituto. A participação não era obrigatória, os alunos poderiam optar em apenas realizar uma prova de recuperação ao final do bimestre.

Para surpresa das autoras, houve a inscrição de 73 alunos. Sendo assim, organizaram-se as turmas distribuindo-as em dois grupos, sendo 38 alunos do curso de Informática e 37 alunos do curso de Edificações, com encontros quinzenais para cada grupo. No final do projeto de extensão foram implementadas nove oficinas pedagógicas de matemática que abordaram os conceitos de matemática básica (operações, potenciação, radiciação, geometria plana); equações e funções (gráficos e aplicações no cotidiano).

No presente relato, destaca-se, primeiramente, a importância da legislação para o bom funcionamento dos cursos técnicos integrados. Além disso, aborda-se como o projeto foi desenvolvido, levando em conta seus impactos positivos no processo de ensino e aprendizagem, os quais são evidenciados nos resultados das avaliações dos alunos e também para a formação profissional dos envolvidos.

\section{0 ensino da matemática nos cursos de técnicos}

Com a aprovação da Lei de Diretrizes e Bases da Educação Nacional (Lei 9.394/96), alterou-se a estrutura da Educação Profissional e Tecnológica, regulamentado por meio do Decreto no 2.208/97, que determinou a desvinculação dos cursos técnicos do ensino médio, indicando que estes seriam ofertados como uma modalidade de ensino.

No entanto, o Governo Fernando Henrique Cardoso (1995-2002), com a Lei de Diretrizes e Bases da Educação Nacional, evidenciou o seu descaso com esta modalidade de ensino, o qual, na prática, concretizava-se a divisão entre o ensino propedêutico versus o ensino profissional (GHEDIN, 2013). Segundo Kuezer e Grabowski (2006):

Um dos grandes desafios a serem enfrentados pelo governo e pela sociedade civil é a construção de uma proposta de gestão da educação profissional que seja capaz de envolver todos os segmentos sociais e organizar instâncias e espaços públicos de discussão e deliberação que superem a fragmentação existente e produzam resultados socialmente reconhecidos no que tange à qualificação dos que vivem do trabalho (KUEZER; GRABOWSKI, 2006, p. 311). 
Ensino de Matemática no Curso Técnico Integrado em Edificações e Informática

Em 2004 houve uma revogação do Decreto 2.208/97 pelo Decreto 5.154/04. E em 2008, a Lei 11.741 modificou a Lei de Diretrizes e Bases da Educação Nacional (Lei 9.394/96), adicionando uma seção que se resumia no Decreto 5.154/04. Ficou estabelecida a seção "Da Educação Profissional Técnica de Nível Médio" que, resumidamente, diz:

Será desenvolvida de forma sistematizada em instituições próprias ao ensino, inscreve-se no âmbito da educação escolar e articula-se à formação básica, que deve ser comum a todos os brasileiros, de modo a assegurar-lhes a formação indispensável ao exercício da cidadania, à efetiva participação nos processos sociais e produtivos e, à continuidade dos estudos, na perspectiva da educação ao longo da vida (KUEZER; GRABOWSKI, 2006, p. 298).

O Instituto Federal do Paraná - Campus de Foz do Iguaçu - oferece o curso Técnico Integrado em Edificações e Informática. A Matriz curricular vigente no período de desenvolvimento no projeto de extensão tinha quinze disciplinas do primeiro ano do ensino médio distribuídas em diferentes cargas horárias. A Matriz curricular no curso Técnico Integrado em Informática vigente no período de desenvolvimento no projeto de extensão totalizava dezesseis disciplinas do primeiro ano do Ensino Médio, também distribuídas em diferentes cargas horárias.

Evidencia-se o papel do professor, pois a organização curricular ocorre por disciplinas, como apontam Araujo e Hypolito (2013). Sendo assim, apesar da possibilidade vislumbrada pelo Decreto 5.154/04, de um ensino integrado da educação profissional e educação básica em curso de nível médio, há uma influência cultural no momento de construção de um novo currículo nas instituições. Por essa razão, o professor necessita, de fato, considerar que é necessário e possível vislumbrar uma proposta de ensino integrado, no qual haja uma colaboração entre os pares e uma nova proposta para o ambiente de trabalho; não havendo - nesse - espaços para disputas de carga horárias.

Ciavatta (2005) sublinha ser fundamental o ambiente de colaboração na formação de caráter integrado, pois este diálogo entre as disciplinas da formação geral e específica implica em considerar que a formação de caráter integrado não se reduz ao preparo para o mundo do trabalho.

\subsection{Discutindo os resultados}

Ao propor um projeto de extensão com alunos do primeiro ano do ensino médio do curso Técnico Integrado em Edificações e Informática, surgiu o desafio de elaborar oficinas pedagógicas que oportunizassem aos jovens um novo olhar sobre a matemática, pois os 
Ensino de Matemática no Curso Técnico Integrado em Edificações e Informática

participantes apresentavam conceitos baixos na disciplina de matemática, e também nas disciplinas de formação específicas que necessitam desta disciplina de formação geral.

Considera-se os conceitos de notas dos alunos apenas como indícios, visto que vários são os fatores que influenciam esses resultados. Ao propor uma atividade para investigar em quais conteúdos os alunos tinham dificuldades, todavia, foi identificado, após analisar as resoluções dos alunos, que estes apresentavam dificuldades em conceitos de matemática básica. É importante sublinhar que o diálogo com os professores das disciplinas de formação específica nos ajudaram também a pensar em oficinas que favorecem aos alunos a perceberem a integração entre as formações. Foram então elaboradas oficinas utilizando diferentes tipos de atividades que contribuíssem para o processo de ensino e aprendizagem, sendo que as mais conhecidas são os exercícios, os problemas, as investigações e os projetos.

Nas primeiras oficinas utilizou-se os exercícios que são caracterizados por Ponte (2005) como atividades nas quais os alunos põem em prática o que aprenderam, utilizando conhecimentos adquiridos sem a necessidade de uma reflexão maior sobre a mesma. Dessa forma, há uma consolidação do conhecimento. Neste sentido, como objetivou-se primeiramente entender as dificuldades, os exercícios nos auxiliaram. Utilizando como referências Bittar e Freitas (2005) e Grasseschi et al. (2002), trabalhou-se os conceitos de matemática básica (operações, potenciação, radiciação, geometria plana) e equações do primeiro e segundo graus. Ao debater com os alunos para entender-se como eles se apropriavam da resolução de equações, ficou evidenciado que deveria ser retomar o conceito de equação, visto que os alunos realizavam os procedimentos de forma mecânica, sem entender o que seria equivalência, variável, incógnita, sentença matemática aritmética e algébrica, membros e termos algébricos. Explorou-se os conceitos, utilizando dos princípios aditivos e multiplicativos na resolução de equações.

Dessa forma, foi proposta a resolução de problema tendo como fundamentos teóricos Onuchic e Alevatto (2004), pois as autoras consideram uma importante metodologia de ensino que favorece aos professores trabalhar os diferentes conceitos e procedimentos matemáticos, compreendendo assim a metodologia de resolução de problemas como uma oportunidade de ensinar por meio de resolução do problema, em um espaço rico no qual os alunos socializam suas respostas. Além disso, são concomitantemente estimulados a pensar a respeito de seus conhecimentos.

Solicitou-se aos alunos, no decorrer da implementação das oficinas pedagógicas, que utilizavam a metodologia de resolução de problemas, que formassem grupos para discutir as situações problemas e socializassem seus pensamentos. Neste momento, o papel dos extensionistas era de possibilitar aos alunos pensar e acompanhar suas explorações na busca de 
Ensino de Matemática no Curso Técnico Integrado em Edificações e Informática

um consenso de todos os envolvidos, incentivando um aprendizado a partir dos problemas, como apresentado na Figura 1:

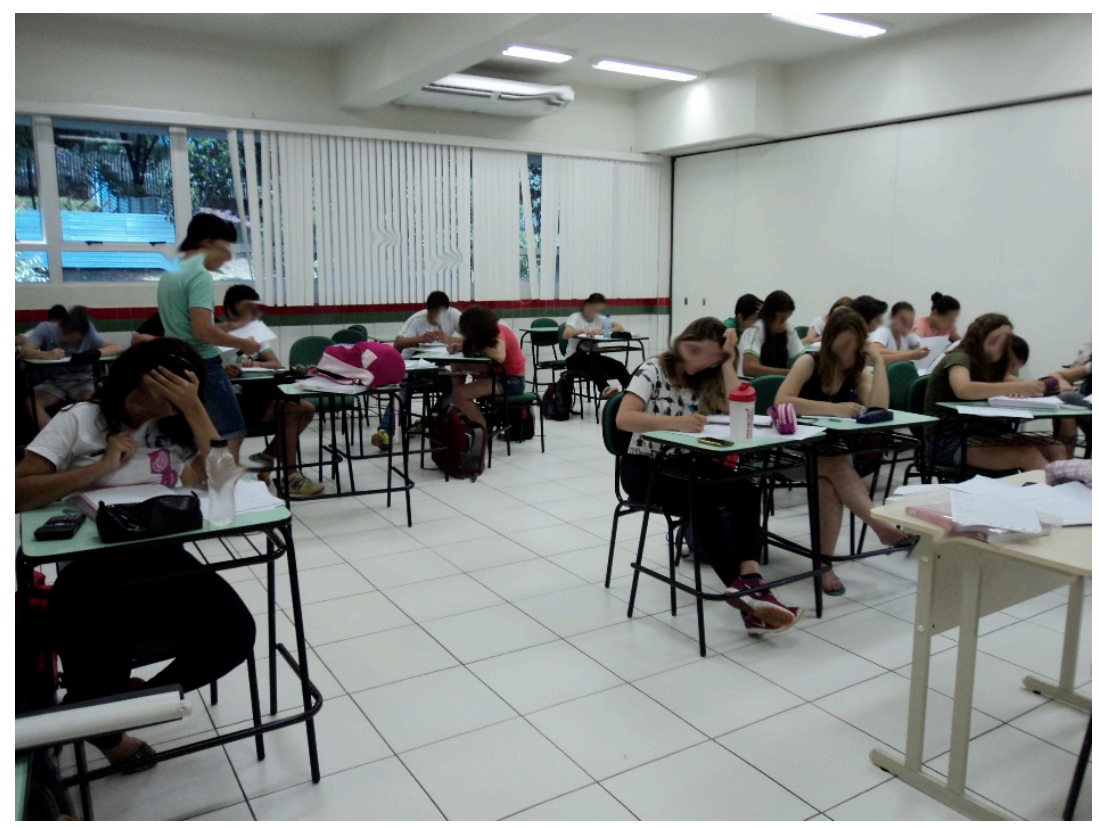

Figura 1: Alunos do curso integrado de edificações resolvendo problemas. Fonte: Autoras.

As situações problemas desenvolvidas foram adaptados dos textos de Duea et al. (1997) e de GrasseschI et al. (2002). A escolha destes problemas se deve ao fato de que eles mostraram ser pertinentes para explorar o conceito de equação de outro modo, favorecendo que expusessem diferentes maneiras de expressar uma mesma igualdade, levando os alunos a questionarem o que de fato é uma equação. Além disso, foram elaboradas cinco oficinas de duas horas cada, que totalizaram dez horas em cada grupo, sobre o conceito de função do $1^{\circ}$ e $2^{\circ}$ grau, logaritmos e exponenciais (gráficos e aplicações no cotidiano). Na elaboração das oficinas, também utilizou-se exercícios e resoluções de problemas.

Cumpre lembrar que a referência principal foi Tinoco (2009), pois as atividades elaboradas possibilitam ao professor trabalhar o conceito de função por meio das representações entendidas aqui como gráfica, tabular e algébrica. Além do mais, as atividades também favorecem aos professores um ambiente no qual os alunos são convidados a socializar suas respostas indo ao encontro do referencial adotado a respeito de resolução de problemas. Neste sentido, ao final de cada oficina, propôs-se diferentes instrumentos avaliativos. As participações nas diferentes oficinas contribuíram para a melhora dos conceitos dos alunos Figura 2 (a seguir). 
Ensino de Matemática no Curso Técnico Integrado em Edificações e Informática
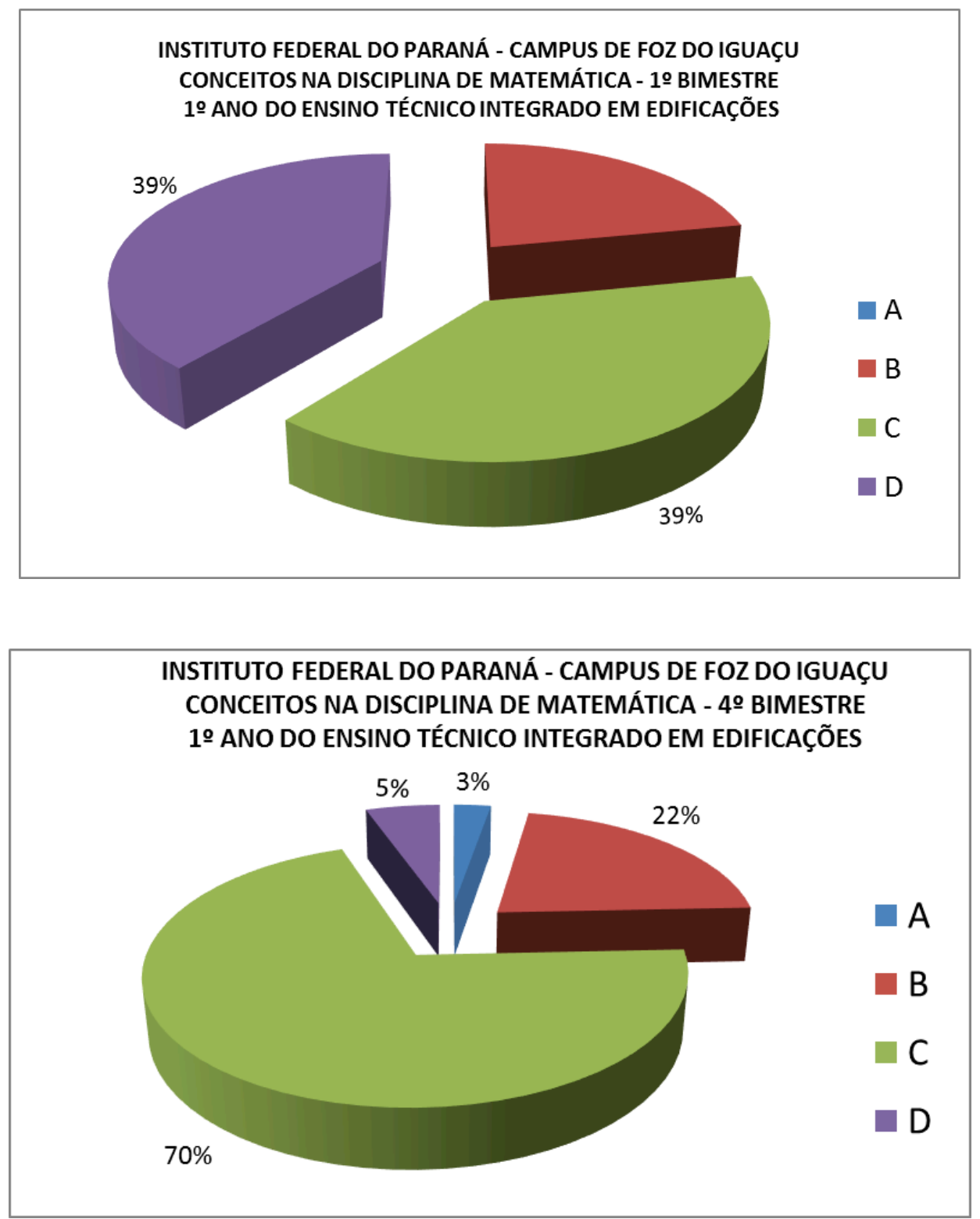

Figura 2: Composição com a comparação dos conceitos obtidos pelos alunos participantes do projeto de extensão em diferentes momentos.

Fonte: Elaboração própria.

Analisando os gráficos pode-se verificar que houve uma diminuição drástica nos alunos que estavam com o conceito " $\mathrm{D}$ ", que muito provavelmente entrariam para estatísticas dos reprovados em matemática. No decorrer do projeto, observamos que, a cada oficina, os alunos se envolviam, sentindo-se mais confiantes, o que contribuiu para o seu desenvolvimento matemático. Os professores envolvidos e futuros professores também refletiam a respeito da importância do seu envolvimento consciente, buscando soluções para os problemas e compreendendo suas responsabilidades e limitações. 


\section{Algumas considerações}

As ações desenvolvidas no decorrer do projeto de extensão durante o segundo semestre de 2013 com os alunos do primeiro ano do curso Técnico Integrado em Edificações e Informática do Instituto Federal do Paraná - Campus de Foz do Iguaçu foram decisivas para os alunos modificarem sua visão do ensino da matemática. Observou-se, ainda, que os alunos necessitam argumentar, comparar e socializar suas estratégias, utilizando-se de atividades que os aproximem de diferentes áreas dos conhecimentos.

Cabe registrar que os conceitos matemáticos em geral são apresentados utilizando apenas a metodologia de exercícios. Além disso, como aponta Ponte (2005), os professores podem sim utilizar exercícios no contexto escolar, mas estes devem ser apenas uma das possibilidades, uma vez que há diferentes metodologias de ensino que contribuem para os alunos participarem ativamente das oficinas desenvolvidas no projeto.

O projeto de extensão auxiliou, também, disciplinas exatas dos cursos de Edificações e Informática, pois se trata de uma área do conhecimento que, além de estar integrada e relacionada a outras, possui uma lógica interna que estabelece a conexão entre diferentes temas que possuem aproximações ou semelhanças de estratégias e de situações problema.

Ao elaborar as diferentes oficinas, buscou-se um diálogo com os professores das demais disciplinas para que, de fato, as atividades propostas possibilitassem uma formação integradora visto que apesar da mudança na regulamentação para Educação Profissional Técnica de Nível Médio ainda há um longo caminho para que se atinja os objetivos propostos.

Diante disso, a extensão universitária aproximando os futuros professores de matemática deste ambiente social proporciona também que estes profissionais reflitam que o diálogo com os colegas de trabalho das diferentes áreas do conhecimento é o caminho inicial para mudanças. Contudo, estas mudanças não ocorrerão por decretos, mas somente se os professores acreditarem na importância de uma formação integrada.

\section{Referências}

ARAUJO, J. J.; HYPOLITO, Á. M. A Construção Curricular em um Curso Técnico Integrado ao Ensino Médio: cultura escolar e comunidades disciplinares. In: TURA, M. L. R.; GARCIA, M. M. A. (orgs.) Currículo, Políticas e Ação Docente. Rio de Janeiro: Ed. UERJ, 2013, p. 223-238.

BRASIL. LDBEN 9394/96. Lei no 9394, de 20 de dezembro de 1996. Brasília - DF, 1996.

BRASIL. Decreto n.2.208, de 17 de abril de 1997.

BRASIL. Decreto n. 5.154, de 23 de julho de 2004. 
Ensino de Matemática no Curso Técnico Integrado em Edificações e Informática

CIAVATTA, M. A formação integrada: a escola e o trabalho como lugares de memória e identidade. In: FRIGOTTO, G,; CIAVATTA, M.; RAMOS, M. (orgs.). Ensino Médio integrado: concepções e mudanças. São Paulo: Cortez, 2005.

DUEA, J. et al. Resolução de Problemas com o uso da calculadora. In: KRULIK, S.; REYS, R.E. (orgs). A Resolução de Problemas na Matemática Escolar. 4 ed. São Paulo: Atual, 1997, p. 165-176.

GRASSESCHI, M. C.; PROMAT: projeto oficina de matemática. São Paulo: FTD. 2002.

GHEDIN, E. O Ensino médio no Brasil e a ausência de um projeto de formação cultural para o país In: PIMENTA, S. G.; PINTO, U. A. (orgs.). 0 papel da escola pública no Brasil contemporâneo. São Paulo: Edições Loyola, 2013.

KRULIK, S. A resolução de problemas na matemática escolar. São Paulo: Atual, 1997.

KUEZER, A. Z.; GRABOWSKI, G.. Educação Profissional: desafios para a construção de um projeto para os que vivem do trabalho. Perspectiva, Florianópolis, v.24, n. 1, p. 296-318, jan/jun. 2006., p. 297-318.

ONUCHIC L. R. Novas Reflexões sobre o ensino-aprendizagem de matemática através da resolução de Problemas. In: BICUDO, M. A; BORBA, M. (orgs). Educação Matemática - pesquisa em movimento, São Paulo, Editora Cortez, 2004.

PONTE, J. P. Gestão Curricular em Matemática. Lisboa: APM, 2005.

SIGNORINI, M. B. Crianças, algoritmos, e sistema de numeração decimal. Dissertação (Pós-graduação para a ciência e o ensino de matemática) - Universidade Estadual de Maringá, Maringá - PR, 2007.

TINOCO, L. A. A. Construindo o conceito de função. Rio de Janeiro: Projeto Fundão, 2009. 
Ensino de Matemática no Curso Técnico Integrado em Edificações e Informática

Mathematics Teaching in the Integrated Building and Computing Technician Course: reflections about an accomplished action

\begin{abstract}
The aim of this article is to present reflections about the contributions for the mathematical development provided by 1 st grade students of the Integrated Building and Computing Technician Course of the Federal Institute of Paraná - Campus of Foz do Iguaçu (Brazil). These contributions were accomplished during the participation in a weekly extension project developed in the second semester of 2013. The results of the students' evaluations, which were made during the project, indicated gradual improvement in school performance in mathematics and related subjects. Furthermore, it was noticed that the offer of the project's activities in the opposite turn and in a facultative manner, with different methods to approach the contents and the evaluation, created an environment with questioning and autonomy for the teaching and learning process.
\end{abstract}

\section{Keywords}

Extension; institutional partnership; educational workshops.

Original submetido em: 25 mai. 2016

Aceito para publicação em: 30 jul. 2016

\section{Enseñanza de la Matemática en el Curso de Técnico Integrado de Edificación y Informática: reflexiones sobre una acción tomada}

\section{Resumen}

El objetivo de este trabajo es presentar reflexiones de las contribuciones al desarrollo matemático de los estudiantes del 1er año del Curso de Técnico Integrado de Edificación y Informática del Instituto Federal de Paraná Campus de Foz de Iguazú (Brasil), que tuvo lugar durante la participación del proyecto de extensión desarrollado por semana en segunda mitad del año 2013. Los resultados de las evaluaciones de los alumnos participantes en el proyecto mostraron una mejora gradual en el rendimiento escolar en matemáticas y disciplinas relacionadas. Además, se observó que la prestación de las actividades del proyecto en el turno contrario y de forma voluntaria, con diferentes maneras de abordar el contenido y evaluación proporcionó una oportunidad de un entorno crítico y la autonomía en el proceso de enseñanza y aprendizaje.

\section{Palabras clave}

Extensión; asociación institucional; talleres educativos

Sobre as autoras:

Susimeire Vivien Rosotti de Andrade

Professora de Matemática na Universidade Estadual do Oeste do Paraná Campus Foz do Iguaçu. Doutoranda no Programa de Pós-graduação em Educação Matemática da Universidade Federal do Mato Grosso do Sul; mestre em Educação para a Ciência e a Matemática pela Universidade Estadual de Maringá (2012); licenciada em Matemática (2001) e especialista em Educação Matemática pela Universidade Estadual do Oeste do Paraná (2005). Participa dos Grupos de Pesquisa Formação e Educação Matemática (UFMS) e Formação de Professores de Ciências e Matemática da (UNIOESTE).

\section{Adriana Stefanello Somavilla}

Professora efetiva do Ensino Básico, Técnico e Tecnológico do Instituto Federal do Paraná (IFPR)/ Campus de Foz do Iguaçu. Mestranda no Programa de PósGraduação em Ensino da Universidade Estadual do Oeste do Paraná - Campus Foz do Iguaçu. Graduada em Matemática/Licenciatura Plena pela Universidade Federal de Santa Maria (1997). Especialista pelo Centro Universitário Franciscano de Santa Maria (2000). Pesquisadora do Núcleo de Estudos e Pesquisas em Educação, Cultura e Sociedade (NEPECS). 